\title{
Pandemia e estudantes em casa: currículo escolar e novas formas de aprendizagem dos estudantes no contexto de Parintins (AM)
}

\section{Pandemic and students at home: school curriculum and new ways of learning for students in the context of Parintins, Amazonas}

\author{
Fabiane Andrade Batista ${ }^{1 *}$, Kézia Siméia Barbosa Martins ${ }^{1}$
}

\begin{abstract}
RESUMO
O cenário de crise mundial gerada pela Covid-19 impulsionou esta pesquisa acerca da aprendizagem das crianças, as limitações no processo de ensino e as novas configurações no contexto familiar frente aos estudos em casa por meio do Ensino Remoto. Financiada pelo Programa Institucional de Bolsas de Iniciação Científica - PIBIC/FAPEAM (Fundação de Amparo à Pesquisa do Estado do Amazonas), a investigação focaliza uma problemática que modificou a estrutura, organização curricular e os processos de ensino e aprendizagem escolar. A atualidade do tema, a realidade do ensino- aprendizagem no município de Parintins/Amazonas e a necessidade de registrar as experiências vivenciadas no período pandêmico justificam a relevância da pesquisa. Os fundamentos teóricos foram Sacristán (2013), Lopes e Macedo (2011), Macedo (2008), Silva (2007); Palú, Schütz, Mayer (2020), Oliveira, Gomes, Barcellos (2020), Guizzo, Marcello, Müller (2020), Dalben (2020) e Bases Legais. A abordagem metodológica é Qualitativa, realizada por meio da Pesquisa de campo com utilização de entrevistas e diálogos com coordenadores pedagógicos, pais e estudantes, o que possibilitou melhor compreensão do fenômeno educacional.
\end{abstract}

Palavras-chave: Pandemia; Currículo Escolar; Estudo em casa; Ensino fundamental.

\begin{abstract}
The global crisis scenario generated by Covid-19 boosted this research on children's learning, the limitations in the teaching process and the new configurations in the family context in front of home studies through Remote Teaching. Funded by the Institutional Program for Scientific Initiation Scholarships PIBIC/FAPEAM (Research Support Foundation of the State of Amazonas), the investigation focuses on a problem that has changed the structure, curriculum organization and the processes of school teaching and learning. The topicality of the theme, the reality of teaching-learning in the city of Parintins/Amazonas and the need to record the experiences lived during the pandemic period justify the relevance of the research. The theoretical foundations were Sacristán (2013), Lopes and Macedo (2011), Macedo (2008), Silva (2007); Palú, Schütz, Mayer (2020), Oliveira, Gomes, Barcellos (2020), Guizzo, Marcello, Müller (2020), Dalben (2020) and Legal Bases. The methodological approach is Qualitative, carried out through field research using interviews and dialogues with pedagogical coordinators, parents and students, which enabled a better understanding of the educational phenomenon.
\end{abstract}

Keywords: Pandemic. School curriculum; Students at home; Elementary School.

\footnotetext{
${ }^{1}$ Universidade Federal do Amazonas. E-mail: fabiandrade1806@gmail.com
} 


\section{INTRODUÇÃO}

O cenário de crise mundial gerada pela Covid-19 gerou impactos na aprendizagem das crianças, limitações e entraves no processo ensino-aprendizagem escolar e novas configurações no contexto familiar frente aos estudos em casa por meio do Ensino Remoto. A atualidade do tema, a realidade do ensino- aprendizagem no município de Parintins-Amazonas e a necessidade de registrar as experiências vivenciadas no período pandêmico justificam a relevância da pesquisa. Estudantes afastados das salas de aula, o isolamento social, a necessária continuidade dos estudos escolares, obrigaram gestores e profissionais da área da educação, nas mais variadas escalas, a criar estratégias para garantir que os alunos continuassem aprendendo. Daí as questões: há garantia de aprendizagem para as crianças em tempos de pandemia? Como as famílias se organizaram para este momento?

A pesquisa, desenvolvida entre 2020/2021, financiada pelo Programa Institucional de Bolsas de Iniciação Científica - PIBIC/Fapeam (Fundação de Amparo à Pesquisa do Estado do Amazonas) focaliza uma problemática que modificou a estrutura, organização curricular e os processos de ensino e aprendizagem escolar, a qual trouxe impactos irreversíveis para a educação conforme declaração e estudos diversos (PLAPLER, 2020; BOTO, 2020, ENSINO, 2020). É ilusório achar que professores terão todo tempo para executar planos e acompanhar seus alunos por meio de recursos tecnológicos; pais com tempo, possibilidade e habilidade para executar juntamente com seus filhos as tarefas e atividades propostas por meio de WhatsApp, radio-aulas, mensagens de voz, vídeo-aulas; e alunos concentrados e disponíveis a desenvolver as tarefas cotidianamente. Segundo Blikstein et al (2020) há ainda o desafio da equidade. No Brasil, alunos mais carentes não têm como seguir cursos online. Além de terem menor acesso à internet e computadores em casa, eles dispõem de menor espaço físico para assistir a aulas virtuais.

Trazer à tona um diagnóstico de como foram desenvolvidas as atividades curriculares, quais seus efeitos, limitações e condições de execução, a partir das orientações das Secretarias de Educação e das orientações do Conselho Nacional de Educação (CNE) que no final do mês de abril aprovou as diretrizes para orientar escolas da educação básica e instituições de ensino superior durante a pandemia do coronavírus (ESTRELLA; LIMA, 2020). Segundo as autoras, o documento foi aprovado em plenário 
virtual pelos conselheiros, com orientações e sugestões para todas as etapas de ensino, da Educação Infantil ao Ensino Superior. O parecer foi elaborado com a colaboração do Ministério da Educação (MEC) e aprovado pelo CNE, com o objetivo de orientar estados, municípios e escolas sobre as práticas que devem ser adotadas durante a pandemia, além de propor normas nacionais gerais. A reorganização dos calendários é de responsabilidade dos sistemas de ensino. Para o Ensino Fundamental - anos iniciais, o documento sugere que as redes de ensino e escolas orientem as famílias com roteiros práticos e estruturados para acompanharem a resolução de atividades pelas crianças. No entanto, as soluções propostas não devem pressupor que os "mediadores familiares" substituam a atividade do professor. As atividades não presenciais propostas devem delimitar o papel dos adultos que convivem com os alunos em casa e orientá-los a organizar uma rotina diária. Assim, as escolas traçaram estratégias pedagógicas para não deixar os alunos sem estudar no interior de suas casas. Sabe-se que é difícil e complexo dar conta de um currículo com aulas presenciais, imagine ajustar esta tarefa à crise e tensão vivenciadas na pandemia.

As bases teóricas acerca do Currículo Escolar fundamentaram-se em Sacristán (2013), Lopes e Macedo (2011), Macedo (2008), Silva (2007). Quanto à Pandemia e educação escolar foram analisados estudos e discussões de Palú, Schütz, Mayer (2020), Oliveira, Gomes, Barcellos (2020), Guizzo, Marcello, Müller (2020), Dalben (2020). A abordagem metodológica é Qualitativa, realizada por meio da Pesquisa de campo seguindo os protocolos de segurança, termos de consentimento e autorização das escolas e famílias selecionadas, bem como usos de ferramentas tecnológicas. Os instrumentos para coleta e produção dos dados foram: questionário semiaberto realizado com 10 (dez) famílias selecionadas; e conversa dialogada com 20 (vinte) estudantes das famílias selecionadas que aceitaram participar do projeto, para conhecer as experiências de aprendizagem vividas no tempo do isolamento e distanciamento da escola decorrentes da pandemia.

\section{Curriculo escolar e Pandemia da Covid-19: diálogos e reflexões teóricas}

Mais do que um documento que contêm diretrizes e conteúdos trabalhados em uma escola, o currículo segundo Sacristán (2013), é um componente formador da realidade no qual vivemos, o currículo dá forma à educação. O currículo, assim como as teorias que o explicam, é um território de intensa discussão e estudos. O autor destaca que "são poucos elementos, fenômenos, atividades e fatos da realidade escolar que não têm 
qualquer implicação no currículo e não são afetados por ele" (2013, p.10). Portanto é inconcebível pensar em práticas educacionais sem articular a um currículo competente e o estabelecimento de um projeto político pedagógico, pois os mesmos norteiam a realidade do sistema educacional.

O debate sobre o campo do Currículo e sua conceituação é necessário para que saibamos compreende-lo e conhecer as teorias que o cercam na educação. No Brasil, a questão curricular foi influenciada tanto pelas perspectivas técnicas como críticas, principalmente vinculadas à inquietação a respeito do conhecimento, em torno do que ensinar A pergunta sobre "qual" conhecimento é o mais válido, nos aproxima do que vem a ser objeto do currículo, apontando diferentes perspectivas. Silva (2007, p. 29) enfatiza que o currículo está ligado a interesses e conceitos das classes dominantes, desfavorecendo os outros grupos sociais. Afirma que o currículo escolar, se baseado na cultura dominante, ele se expressa na linguagem dominante e é transmitido através do código cultural dominante. Diante disso, as práticas curriculares eram [e são] consideradas um espaço de defesa das lutas sociais e culturais.

As diferentes linhas de pensamentos das teorias abordadas subsidiam as reflexões e análises atuais sobre o campo curricular. Em síntese, o currículo é a base da escola, articula todos seus recursos e diz respeito aos seus objetivos e conteúdo, proporcionando aos alunos o ingresso na cultura letrada e acesso aos diversos saberes. Segundo Moreira (2007, p. 76) “[...] o currículo no seu processo de construção do conhecimento não resulta apenas de experiências trazidas de fora para dentro do espaço escolar. O currículo é um espaço vivo de construção de conhecimento, resultante do pensamento, das experiências de sujeitos e das suas de natureza histórica, social e biológica”. Tudo isso está articulado à identidade e subjetividade na formação dos indivíduos, uma vez que escola precisa estar atenta às necessidades dos alunos, dando ênfase a um currículo que dialogue continuamente com o cotidiano e as formas de aprendizagem.

Partindo destas discussões, indagamos quais os impactos causados no currículo diante dos desafios enfrentados pela escola de Educação Básica no contexto de pandemia da Covid-19? Visto que, devido ao isolamento social, consequentemente houve a suspensão das aulas presenciais por todo o mundo, em todas as modalidades e níveis de ensino. Além da grave crise sanitária no Brasil, que teve início no estado do Amazonas 
no dia 13 de março de $2020^{2}$, onde o primeiro caso de covid-19 foi confirmado, causando posteriormente o colapso no sistema de saúde, em razão do grande número de infectados pelo vírus, a pandemia gerou problemáticas ao sistema de ensino, causando um cenário de incertezas e impactos na vida da comunidade escolar.

O Ministério da Educação do Brasil (MEC), diante da impossibilidade de aulas presenciais, autorizou o Ensino Remoto como alternativa, onde cada instituição educacional reorganizou o calendário e como as atividades seriam desenvolvidas de acordo com a realidade dos alunos, adaptando aulas pela internet, pela TV, por mensagens em redes sociais, pela rádio local e por atividades impressas.

No entanto nem sempre as famílias possuem condições sociais e econômicas para que ocorra tal processo de modo mais acessível possível. Palú (2020) ressalta que a reação do mundo diante da pandemia mostra as consequências de uma sociedade em que os direitos não alcançam a população de modo igual, impactando, principalmente, no direito das minorias e, nesse caso específico, no direito à vida, direito reconhecido como inalienável, mas que nesse momento pode ser negado às parcelas da população pela sua condição econômica.

É preciso reconhecer que este cenário pandêmico causa problemas emocionais além dos estimados, envolvendo a situação de isolamento e do próprio vírus, a ansiedade em relação ao contágio e as tensões em torno dos conteúdos escolares, que atingem os estudantes e seus familiares. Com isso, o currículo deve estabelecer quais conteúdos e quais habilidades farão parte deste formato de ensino e aprendizagem, tendo em vista o desenvolvimento escolar dos estudantes nas atuais condições. Para Almeida (2020, p. 169) [...] "o currículo do futuro deve ser flexível e aberto à articulação com as múltiplas culturas, à incorporação de questões que emergem da realidade, trabalhando com problematizações, projetos, aprendizagem pela investigação e outras metodologias ativas em experiências curriculares constituídas nas redes”. Feldmann, Sensato, Martins (2020, p. 49) destacam que "muitas questões estiveram e estão presentes: qual o lugar do currículo? Seria o lugar do não lugar, e a mediação pedagógica seria possível pelas plataformas digitais que se fizeram presentes no movimento curricular? E a reinvenção do processo de ensinar e aprender? E os sentimentos dos sujeitos curriculares

\footnotetext{
${ }^{1}$ Fonte: Secretaria de Estado de Saúde. Disponível em:

< http://www.saude.am.gov.br/visualizar-noticia.php?id=4327> Acesso: 20 mar. 2021.
} 
envolvidos?". Quantos questionamentos e incertezas encorparam-se neste cenário inesperado, ainda inconcluso e de muitas incertezas.

\section{Currículo escolar e os desafios da escola de Ensino Fundamental: novos contextos, formatos e propostas.}

O Brasil assim como outros países, enfrenta um momento de desafios, com novos planejamentos e formulações em relação ao cenário educacional que causou mudanças nas instituições de ensino, na vida dos alunos, pais e professores. No início da pandemia, o ensino remoto que era apenas uma estratégia emergencial e temporária utilizada no período de isolamento social, se prolongou e se tornou a única possibilidade de os estudantes continuarem os estudos, procurando manter as atividades curriculares em 2020 e 2021.

O parecer do Conselho Nacional de Educação (CNE) enfatiza os impactos causados pela pandemia na educação: 1) comprometimento do calendário escolar de 2020; 2) perdas de aprendizagem dos estudantes; 3) Danos emocionais e sociais para estudantes e famílias, ligados principalmente aos fatores econômicos e problemas de saúde, ou violência familiar e 4) Aumento do abandono e evasão escolar. Sobre a primeira questão, as instituições de Educação Básica foram dispensadas da obrigatoriedade de observar o mínimo de 200 dias letivos de trabalho escolar, porém com a carga horária mínima de 800 horas.

De acordo com o CNE, em 28 de abril, o Parecer CNE/CP n. 05/2020 (BRASIL, 2020) dispõe sobre a Reorganização do Calendário Escolar e oferece a possibilidade das atividades não presenciais para cumprimento da carga horária mínima anual, diante da pandemia do coronavírus. Para os anos iniciais do Ensino Fundamental, o documento aborda sobre algumas dificuldades em relação à alfabetização, mas que é possível a realização de atividades pedagógicas com as crianças dessa etapa, destacando [...] que as redes de ensino e escolas orientem as famílias com roteiros práticos e estruturados para acompanharem a resolução de atividades pelas crianças. (p.11). Segundo Guizzo, Marcello e Müller (2020, p.4), em tempos de pandemia, os procedimentos tecnológicos provocam alterações e produzem reajustes de relações entre professoras e crianças, entre crianças e responsáveis e entre responsáveis e professores. A mediação propiciada pelas tecnologias emerge, então, como um esforço para que os laços sejam mantidos e parece, 
pois, buscar naturalizar e fortalecer os usos da tecnologia como facilitadores da aprendizagem, das relações interpessoais e não como práticas excludentes e desiguais.

As atividades curriculares e pedagógicas não presenciais, que acontecem por meio de vídeo aulas, redes sociais, televisão, rádio, material didático impresso, entre alternativas, não se caracterizam como substituição das atividades presenciais, mas utilizam os meios digitais para desenvolver seus objetivos de ensino e aprendizagem presentes no currículo escolar. O ensino remoto visa a interação do aluno e professor no mesmo horário das aulas presenciais, mantendo a rotina da sala de aula através das ferramentas tecnológicas. Os conteúdos são elaborados pelos professores da disciplina, seguindo o calendário proposto no plano de aula, onde os alunos fazem seus questionários por meio de transmissões ao vivo ou através das redes sociais, principalmente o Whatsapp, havendo interação diária e frequente com o educador, com o objetivo de participação e discussões nas aulas, feedbacks e contribuições dentro do ambiente virtual.

Além disso, para que ocorra a realização de tais atividades, o parecer destaca algumas sugestões como: aulas gravadas para televisão organizadas pela escola ou rede de ensino de acordo com o planejamento de aulas e conteúdo ou via plataformas digitais; lista de atividades e exercícios, sequências didáticas, elaboração de materiais impressos compatíveis com a idade da criança para realização de atividades (leitura, desenhos, pintura, recorte, dobradura, colagem, entre outros); distribuição de vídeos educativos (de curta duração) por meio de plataformas on-line, mas sem a necessidade de conexão simultânea seguidos de atividades a serem realizadas com a supervisão dos pais; realização de atividades on-line síncronas e assíncronas regulares em relação aos conteúdos; estudos dirigidos com supervisão dos pais e exercícios e dever de casa de acordo com os materiais didáticos utilizados pela escola. Contudo, a crise desencadeada pela Pandemia, trouxe desafios às escolas e aos seus sujeitos, gerando incertezas quanto à garantia do direito à educação no Brasil, uma vez que muitos estudantes, professores e famílias não conseguem acompanhar e desenvolver as atividades não presenciais.

Com o avanço e adoção das tecnologias no contexto educacional, é necessária a adaptação da comunidade escolar para superar o período de afastamento da escola. Os professores, gestores, alunos e familiares devem utilizar tais recursos para amenizar o impacto na aprendizagem durante o enfrentamento da pandemia, porém assumir atividades com a mediação das plataformas digitais ainda é um desafio, por conta da falta 
de conhecimento, ou, por limitações tecnológicas para o seu acesso. Os desafios em torno do uso de tecnologias são enfatizados por Guizzo, Marcello, Müller (2020, p. 4):

Professoras precisaram aprender a preparar materiais didáticos (atividades, videoaulas, recados motivacionais etc.), mas também a lidar com aplicativos e/ou ambientes virtuais nos quais disponibilizar esses materiais. Suas rotinas alteraram-se bruscamente, pois, além de planejar, também precisaram aprender a gravar, estar online e sanar dúvidas. Crianças, por sua vez, precisaram aprender não só com suas professoras, cujas aulas virtuais foram disponibilizadas inclusive em plataformas como YouTube, mas também com seus próprios responsáveis, num espaço completamente familiar (suas casas), ainda que num tempo flexível, negociável. Pode-se dizer que essas novas noções de espaço e tempo estão imbricadas com a produção de novos modos de pensar a educação e os processos pedagógicos.

Deste modo, a inserção dos meios digitais no cotidiano dos alunos e professores, além de fornecer um suporte para minimizar os efeitos do distanciamento social, como consequência enfatizaram algumas problemáticas, que já existiam e foram atenuadas no período pandêmico, e uma delas é a exclusão digital. A urgência de adaptações para a continuidade dos estudos evidenciou que muitos lares brasileiros não possuem acesso à internet e acabam sendo privados do processo de aprendizagem. Alves (2020) ainda destaca outros problemas enfrentados pelos pais, referentes a: ausência de computadores em suas casas, já que utilizam os dispositivos móveis para acessar a rede internet; falta de experiência com a interface das plataformas que vem sendo utilizadas para os encontros virtuais, como Google Meet, Teams, Zoom, entre outros; a dificuldade em mediar as atividades que seguem a sequência prevista para as aulas presenciais, exigindo dos pais conhecimento e estratégias para ensinar aos filhos os conteúdos que são cobrados e não ensinados pelos professores.

No Brasil, o cenário comprometido pela grave crise sanitária somada pela intensa desigualdade social, anterior à pandemia, leva a escola além do desafio de organização das aulas remotas, a lidar com a desigualdade educacional, visto que enquanto a rede pública tenta malabarismos para gerenciar a crise causada pela pandemia em todas as áreas, o ensino particular dispõe de melhores recursos para manter uma aprendizagem com qualidade, onde os alunos têm amplo acesso à internet e a diversos meios e ferramentas digitais.

Curriculo escolar e estratégias pedagógicas utilizadas na pandemia com estudantes das escolas de Ensino Fundamental I em Parintins, Amazonas. 
Este tópico discute questões produzidas a partir da entrevista semiestruturada realizada com 01 (uma) coordenadora pedagógica da Secretaria Municipal de Educação (SEMED), Parintins, Amazonas, 6 (seis) coordenadores pedagógicos e 2 (dois) gestores das escolas de $1^{\circ}$ a $5^{\circ}$ ano do Ensino Fundamental que colaboraram com a pesquisa. As escolas serão citadas com nomes fictícios, preservando suas identidades. O objetivo foi identificar quais as estratégias utilizadas para garantir a continuação dos estudos e a aprendizagem a dos estudantes durante a pandemia; e ouvir, conhecer como os gestores da escola pública pensaram, organizaram e lidaram com este momento de enfrentamento à pandemia da Covid-19 na realidade de Parintins, Amazonas.

Inicialmente realizamos uma pesquisa exploratória na Secretaria Municipal de Educação (SEMED) em Parintins, Amazonas junto à coordenação pedagógica para diagnosticar quais estratégias didático-metodológicas estavam sendo utilizadas para manter as crianças estudando e garantir o mínimo de aprendizagem dos conteúdos curriculares durante a pandemia. Identificamos que as escolas públicas municipais de Ensino Fundamental utilizaram recursos midiáticos como a internet, televisão e rádio. Este último foi importante ferramenta para desenvolver as aulas, segundo a entrevista com a coordenadora pedagógica da SEMED: “Os alunos estão tendo orientações e suporte para minimizar perdas na aprendizagem. Sabemos que não é cem por cento, mas é o que foi possível [...] e o rádio foi uma estratégia, principalmente na zona rural, por ter um alcance significativo." O rádio foi o recurso usado para os alunos das escolas municipais do quarto ao nono ano do Ensino Fundamental, focalizando as áreas de Língua Portuguesa e Matemática, considerados como componentes curriculares onde os alunos apresentam maiores dificuldades e dúvidas.

Quanto aos estudantes do primeiro ao terceiro ano do Ensino Fundamental, a coordenadora pedagógica destacou: “[...] os professores vão organizando seus materiais, indicando para as crianças, enviando apostilas para que elas participem das atividades de forma remota, tudo em casa com o auxílio das famílias. Os conteúdos todos foram pautados na BNCC e no Referencial Curricular Amazonense". Verificamos que tais apostilas são organizadas de acordo com o ano e disciplina, geralmente com um conteúdo mais simplificado, produzido com a participação dos professores. A organização e conteúdo para o Ensino Remoto segue as diretrizes e resoluções do MEC e as Diretrizes Pedagógicas para o Regime Especial de Aulas Não Presenciais no Amazonas 
(AMAZONAS, 2021), de modo a garantir a aprendizagem dos conteúdos curriculares durante o período de isolamento social, como afirma a coordenadora pedagógica:

[...] o processo de implementação vem sendo pautado nas diretrizes e nas resoluções que o MEC estabeleceu quando autoriza o ensino remoto, diante disso o sistema se organiza orientando as escolas, os professores e os gestores para que direcionem esse trabalho. Na cidade, na zona urbana, se torna um pouco mais fácil, porque nós temos acesso à internet, as famílias tem acesso a um aparelho celular. Então, ele acontece por meio de grupos de Whatsapp [...] nesses grupos os professores fazem interação com as famílias e ao mesmo tempo vão direcionando as atividades [...] na zona rural, muitos professores e muitas comunidades adotaram a apostila, onde eles vão na comunidade fazer a entrega do material em determinado período e retornam para fazer a coleta dessas apostilas e corrigir. (Coordenadora Pedagógica da SEMED, Parintins/Amazonas)

Ao analisar as estratégias pedagógicas utilizadas no município de Parintins, verificou-se o impacto que o ensino remoto teve na aprendizagem das crianças, já que seus recursos são limitados e escassos. O contato que estudantes estão tendo com os professores é mínimo, por tratar de crianças menores, todas as dúvidas são realizadas pelos pais através de mensagens ou ligações para os professores. Como destaca Palú, Schutz e Mayer (2020) a pandemia revela um cenário de graves problemas sociais que a antecedem e que a partir dela são agravados. Esses atingem principalmente as minorias, as populações menos assistidas, a pandemia não atinge a todos da mesma forma.

Em relação às escolas estaduais, as estratégias utilizadas não diferem muito, porém no estado no Amazonas as Secretarias de Educação implantaram o projeto denominado "Aula em Casa" que teve como objetivo ensinar os conteúdos aos estudantes amazonenses conteúdos por meio da televisão aberta, aplicativo de celular, YouTube e Facebook. A Secretaria Estadual de Educação do Amazonas, com o necessário Ensino Remoto Emergencial no ano de 2020, organizou alternativas pedagógicas para superar o período de isolamento social. Nos anos iniciais do Ensino Fundamental de $1^{\circ}$ ao $3^{\circ}$ ano foram desenvolvidas atividades impressas e o acesso a portais de sites educacionais, que seriam explanados pelos professores para o ensino dos conteúdos escolares. O contato entre os professores com os estudantes e responsáveis também foi realizado via aplicativos de mensagens instantâneas, principalmente por grupos no Whatsapp.

O desenvolvimento do Ensino Remoto nas escolas estaduais do Amazonas, precisamente na capital Manaus, viveu alguns conflitos em relação à possibilidade de retorno das aulas com atividades hibridas nas redes de ensino privada e pública nos meses finais de 2020. A Secretaria de Educação foi cercada de críticas, principalmente por parte 
dos professores e pais, que questionavam o risco de contaminação pelo coronavírus, a falta de equipamentos e acesso à internet, excesso de trabalho docente.

O processo de aprendizagem dos estudantes por meio do Ensino Remoto, tendo como espaço o âmbito familiar, apresenta questões sem resposta, principalmente em torno dos conteúdos curriculares considerados como "perdidos" pelos pais dos alunos.

Nas escolas municipais de Parintins, um dos principais desafios foi o acesso à internet para interação com os professores, visto que muitos alunos são oriundos de classes sociais menos favorecidas. Diante deste impasse, as atividades remotas se dividiram entre elaboração de apostilas e atividades postadas nos grupos de Whatsapp. Como destaca o coordenador pedagógico da Escola Municipal "Flor de Liz": "a maioria não tem acesso à internet, então trabalhamos as atividades remotas através de apostilas, o professor elabora apostila para os alunos do primeiro ao nono ano [...] com duração de quinze dias."

Identificamos que os alunos que não interagem nos grupos ou não entram em contato com os professores são abordados em suas casas, com todo o protocolo de segurança, para a entrega e resolução das apostilas, mas enfrentaram dificuldades: "Infelizmente, temos um grande número de pais que nem telefone tem. Então fica muito difícil manter esse contato [...] e tem a situação também que houve pais que levaram os filhos para o interior". (Coordenador Pedagógico da Escola Municipal Flor de Liz).

Esse ponto foi ressaltado também pelo coordenador pedagógico da Escola Estadual "Pequeno Aprendiz", que destaca o maior desafio da instituição:

[...] de um modo geral, foi à internet para as famílias. Porque aquelas famílias que tem condições eles puderam ajudar, acompanharam o projeto aula em casa, que é todo transmitido on-line. Aquelas famílias que não tem, nem tentaram e outras deixaram de mão mesmo, então foi um desafio para os pais das escolas e nem todas as famílias puderam colaborar. (Coordenador pedagógico da Escola Estadual Pequeno Aprendiz)

As estratégias para o desenvolvimento dos conteúdos curriculares com os estudantes fundamentaram-se no material encaminhado pelas Secretarias de Educação, todavia a realização dessas tarefas não saiu conforme planejado pelos gestores e coordenadores, tendo em vista as dificuldades citadas, as quais afetaram negativamente o ensino e a aprendizagem. 
Uma das alternativas para a aproximação dos alunos com os professores foi a criação de grupos de Whatsapp para cada turma, pois o aplicativo é utilizado com garantia ilimitada de muitas operadoras de telefonia móvel para esse tipo de serviço, além de serem mais acessíveis financeiramente. De 10 (dez) escolas onde foi realizada a pesquisa, somente 01 (uma) não utilizava o aplicativo diariamente como ferramenta de ensino. Entretanto foram identificadas algumas problemáticas relacionadas a criação de grupos e sala virtual por meio deste aplicativo:

Criamos grupos de Whatsapp para todas as turmas, mas a adesão, ela não foi cem por cento, uma base de trinta/ quarenta por cento dos pais não tem o aplicativo nem acesso à internet, que dificulta um pouquinho mais. Até pela qualidade de internet na nossa cidade, a gente sabe que não é muito boa. A escola dispõe de uma internet boa que facilita o trabalho do professor. (Coordenador Pedagógico da Escola Municipal Flor de Liz)

[...] nós fomos desenvolvendo toda uma ação, todo um trabalho com essa família, nós sofremos uma certa resistência por parte de alguns pais em acompanhar e fazer as atividades com as crianças, porque no entendimento de alguns, eles estavam fazendo a função do professor. (Coordenadora Pedagógica da Escola Estadual Educar)

A gestão escolar e coordenação pedagógica lidaram com a resistência das familiares ao novo modelo de ensino, consequentemente afetando o engajamento das práticas de ensino adotadas. Mais difícil ainda no município de Parintins com a instabilidade de uma internet precária que dificulta o trabalho dos professores e da gestão escolar, e dos alunos sem condições para obter dados móveis no celular e que dependem da disponibilidade dos aparelhos celulares dos pais. O que resultou na falta de interação com os estudantes e com os pais, bem como prejudicou o desenvolvimento das atividades curriculares:

Muitos pais saiam do grupo também por várias situações ou psicologicamente, porque não era motivador ou porque não era interessante trabalhar com as mídias por telefone, por vídeo. Eles não queriam fazer um trabalho assim e navegar nas atividades. O que nós fazíamos? [...] Nós conversamos e adaptamos atividades, mudamos horários, fizemos um novo cronograma, um atendimento mais individualizado, alguns conseguimos recuperar outros ainda estavam resistentes, mas não obrigamos [...]. (Coordenadora Pedagógica da Escola Estadual "Educar") 
Um dos pontos enfatizados diz respeito à formação dos professores, que não atendem toda essa mudança no formato de ensino e métodos de aprendizagem dos conteúdos escolares. A implementação das atividades não presenciais demanda dos professores o desenvolvimento do letramento digital e a mobilização do uso dessas ferramentas: "Nossas ferramentas são limitadas e o nosso conhecimento tecnológico também, não estamos preparados o suficiente para atender essa demanda. Nossos professores, nem todos tinham conhecimento sobre as salas de vídeo, aplicativos, várias ferramentas e plataformas." (Coordenador Pedagógico da Escola Estadual Canto do Saber)

Os professores com menos habilidades no uso de tecnologias, segundo as falas continuavam a repetir os mesmos conteúdos e fazendo as mesmas atividades como se o aluno estivesse presencial na sala, mudando somente a ferramenta de comunicação, e isso tornou o Ensino Remoto mais complexo. Na concepção de Almeida (2020) para que um currículo disponha do uso da tecnologia em uma instituição escolar, não deve apenas fazer o uso desses meios em aulas expositivas, mas desenvolver processos educativos mediados pelas tecnologias digitais que sejam interativos, reflexivos, construtivos e contextualizados. Significa impulsionar a leitura crítica e a escrita multisemiótica do mundo. Além da formação dos professores, empenho da gestão escolar e da família, é preciso oferecer infraestrutura e apoio para as instituições escolares, que em tempos de pandemia, foi uma das principais problemáticas.

Como já foi mencionada, uma das estratégias realizadas nas escolas municipais foi o projeto -“Aprendendo em casa pelas ondas do rádio”, transmitidas do estúdio da Rádio Clube de Parintins em conjunto com a Rádio Alvorada e Rádio Tiradentes. Professores e gestores destacaram o bom uso dessa alternativa pedagógica, a qual influenciou positivamente para os estudantes que não tinham acesso à internet com frequência, visto que as aulas no rádio são de segunda a sexta-feira. Como ressalta a gestora da Escola Municipal "Amazônia”:

[...] a ideia das aulas no rádio foi fantástica, ela não atingiu cem por cento, mas foi um percentual bem bacana [...] com exceção da matemática que é um pouco mais complicada, que precisa de visualizações, em tempo real ali com o professor, que foi o que mais dificultou [...] teve pais que adquiriram rádios para poder auxiliar os filhos, outros no próprio celular já têm disponível. Então, de primeira foi difícil fazer esses ajustes, mas também continuamos pelos grupos de WhatsApp. 
As escolas estaduais embora seguissem o mesmo formato, variavam nas estratégias de ensino. A plataforma "Aula em casa” com disposição de vídeos do youtube, apostilas no formato PDF, atividades e sugestões pedagógicas no site, não alcançou um número significativo de estudantes, e a solução foi a elaboração de apostilas e o uso frequente das leituras e atividades dos conteúdos do livro didático.

Já que essa alternativa atingia estudantes que anão mantinham o contato com a escola, fato que aumentou durante o período de pandemia, o professor e a gestão escolar desempenhou o papel de procurar esses alunos.

[...] no segundo semestre, houve uma participação menor e ficaram principalmente aqueles pais que eram mais comprometidos com os alunos. O que fazer com esses alunos? Os alunos que não tiveram participação no projeto Aula em casa, ou, não participaram direto, a escola tem que fazer um plano de estudo, entrar em contato com essas famílias, solicitar, colocar suas estratégias em ação e as crianças tem que vir a escola, pegar esse plano de ação/de estudo pra que elas possam ter o rendimento do primeiro semestre e segundo semestre, gerar um boletim. (Coordenador pedagógico da Escola Estadual "Amazônia")

Segundo o Conselho Nacional de Ensino (CNE), para evitar a evasão escolar, é recomendado que as instituições educativas do Brasil evitem a reprovação dos estudantes durante esse período de pandemia. Cada escola poderá decidir qual a melhor estratégia para avaliar os estudantes, segundo a gestora da Escola Estadual "Educar" em relação à reprovação dos alunos: "não podemos reprovar nenhum aluno, eles não têm culpa. Então nós temos que ajudar esses alunos a adquirir essa nota, onde até o sistema mudou, no ano normal, fora de pandemia, era bimestral as notas e agora é semestral [...]”. Apesar da conclusão do ano letivo para todos, tal problemática pode levar ao baixo rendimento e o aumento nas dificuldades de aprendizagem dos alunos.

Os desafios impostos pelo ensino remoto emergencial devem ser enfrentados pela comunidade escolar, apesar de ser uma alternativa temporária, a criação de estratégias e novos hábitos devem ser realizados, para garantir o mínimo de aprendizagem durante esse período. Segundo Kirchner (2020) mesmo com grandes desafios, temos convicção que estamos vivenciando um período de ruptura educacional, as mudanças estão acontecendo e vão continuar.

Pandemia \& estudantes em casa: novas formas de aprendizagem escolar. 
Desde o mês de março de 2020, as aulas presenciais foram suspensas devido à pandemia de Covid-19, e as escolas de Educação Básica do município de Parintins Amazonas (cidade lócus desta pesquisa), também se reorganizou de acordo com a realidade de cada estado e região, devido a incerteza quanto a data de retorno às aulas nas instituições escolares. Novas formas de ensino tiveram que ser adotadas pensando nas diversas realidades dos estudantes e professores, visto que muitos são oriundos de classes sociais mais baixas, com pouco ou sem acesso a tecnologias digitais.

As escolas públicas municipais e estaduais aderiram também o Ensino Remoto, organizando em aulas on-line via WhatsApp, com projeto "Aprendendo em casa pelas ondas do rádio", e pela plataforma "Aula em casa", com entrega de apostilas elaboradas e impressas para familiares dos estudantes. Todas essas ações foram planejadas de acordo com as secretarias, que seguiram os decretos do Governo do Estado do Amazonas e as orientações do Ministério da Saúde e do Conselho Nacional de Educação.

Entretanto, se na sala de aula com ensino presencial os professores lidam diariamente com diferentes realidades e desafios, muito mais no Ensino Remoto, cujo formato requer uma organização e esforço mais colaborativo com as famílias, especialmente com as crianças dos anos iniciais, pois exigem estratégias didáticas que articulam experiências, vivências relacionadas aos contextos das crianças. Embora os ambientes virtuais facilitem e se mostrem interessantes, pensando em um currículo mais amplo e diverso, a realidade de ensinar os conteúdos curriculares aos filhos em casa é uma tarefa trabalhosa.

As discussões desta sessão correspondem aos resultados obtidos por meio do questionário semiaberto com 10 (dez) famílias selecionadas que aceitaram participar do projeto e as conversas dialogadas com os estudantes dessas famílias, focalizando as experiências de aprendizagem vividas no tempo do isolamento e distanciamento da escola, as dificuldades no desenvolvimento das atividades curriculares e os tipos de tarefas escolares realizadas. Em resposta ao questionário direcionado aos pais, por meio do aplicativo WhatsApp e ligações telefônicas, expuseram sobre o processo e desenvolvimento da aprendizagem dos conteúdos curriculares no interior de suas casas.

É uma experiência diferente, ainda que façamos um esforço para normalizar a situação, a escola faz muita falta, pra mim foi um pouco complicado, $[\ldots]$ primeiro que aqui em casa são quatro crianças de 
diferentes idades. (Mãe de estudantes do $2^{\circ}$ e $4^{\circ}$ ano do Ensino Fundamental)

Foi uma experiência diferente, nunca tinha passado por isso, mesmo porque não tinha ajuda de ninguém, nem do pai dele, pois somos separados, então ficou tudo por mim a responsabilidade do estudo dele. (Mãe de estudante do $2^{\circ}$ ano do Ensino Fundamental)

Com toda essa dificuldade que a gente também teve financeiramente, ter que se preocupar de fiscalizar a tarefa, que é coisa que a gente já fazia, mas dar um pouco mais de atenção foi difícil e tivemos que estudar para ensinar nossos filhos. (Mãe de estudante do $3^{\circ}$ ano do Ensino Fundamental).

Os pais dos alunos enfatizam como esta nova forma de ensino e aprendizagem, com maior necessidade da cooperação da família, afetou a rotina dos lares. Segundo Dalben (2020) “[...] essa realidade das famílias não está sendo fácil. Os quartos se transformaram em escritórios de trabalho, ou de amontoados de gentes que não podem sair para trabalhar ou brincar. Famílias com pessoas que ficaram desempregadas, famílias que perderam entes queridos, famílias convivendo 24 horas com pessoas com transtornos mentais, dentro de casa, famílias convivendo com suas crianças sem espaços para as correrias e brincadeiras tão importantes para o desenvolvimento de cada uma."

Nota-se que as dez famílias entrevistadas enfrentaram desafios para auxiliar as crianças nas atividades escolares, pais, mães que trabalham em casa ou fora de casa, e não conseguem dar atenção necessária às crianças enquanto exercem outras funções obrigatórias ou não têm com quem deixar os filhos em casa. Em relação a esses desafios, Guizzo, Marcello, Müller (2020) destacam que os responsáveis precisaram mediar a relação entre professoras e crianças, reaprender conteúdos até então esquecidos e aprender a lidar com aplicativos e ambientes virtuais: baixar conteúdo, acessar sites de bibliotecas, filmar atividades, tirar fotografias, fazer postagens que comprovem a realização das atividades, o que compõem as condições de possibilidade para a continuidade dos estudos dos filhos. Para todas essas tarefas, precisaram investir tempo em uma nova demanda agora a eles imposta.

Outro ponto identificado envolve as dificuldades com as crianças, principalmente do $1^{\circ}$ a $3^{\circ}$ ano, que estão no processo de alfabetização e sentem mais necessidade do acompanhamento dos professores e pais. No Brasil, o processo de alfabetização das crianças deve ser realizado até o final do segundo ano do Ensino Fundamental I, com a mediação do professor e situações para que os alunos sejam incentivados a desenvolver as habilidades para a leitura e escrita. 
As famílias, diante da rotina de estudos mais intensos no interior das casas, sentiram dificuldades em auxiliar os filhos nesse processo: "eu não tenho tantos conhecimentos de qual melhor forma possível de ensinar em casa sem a escola, então só sigo o que os professores fazem e é difícil porque eles passam muita coisa pra estudar." (Mãe de estudantes do $2^{\circ}$ e $4^{\circ}$ ano do Ensino Fundamental).

\begin{abstract}
Apesar de ele estar avançando, sinto que devo influenciar a melhorar na leitura, e foi nisso que eu vi o quanto é importante estar incentivando a criança pra acompanhar seus resultados, porque eu não percebia alguns problemas de escrita que ele tem, agora posso ver e tentar ajudar a ser melhor [...], mas ensinar a ler e escrever não está sendo uma tarefa fácil, até porque nós adultos aprendemos com métodos diferentes. (Mãe de estudante do $2^{\circ}$ ano do Ensino Fundamental)
\end{abstract}

Dos dez familiares entrevistados, dois estudantes que estão no $2^{\circ}$ e $3^{\circ}$ ano do Ensino Fundamental das escolas estaduais, possuem Transtorno do Espectro do Autismo (TEA). Segundo os familiares destes alunos, a dificuldade de manter a concentração durante as aulas remotas tornou-se ainda maior, levando em conta que a suspensão das aulas no âmbito escolar afeta a socialização e embaraça toda rotina que o aluno mantinha na sala de aula. As incertezas geradas pela pandemia obrigam os responsáveis a buscar novas formas de relacionamento e convivência, mesmo com os efeitos de aprendizados interrompidos e não sabendo muito bem como lidar com a mudança no comportamento das crianças. Em um dos relatos da mãe de um estudante percebe-se a seguinte queixa:

A maior dificuldade foi em relação aos conteúdos escolares, principalmente por compreender que quem ensina é a professora da escola. Mas, agora já me considero sua professora, pois lhe ensino. Tivemos a dificuldade pois como sua linguagem não é tão desenvolvida é necessária uma participação de um profissional especializado. Os materiais não foram adaptados, assim ele realiza as mesmas atividades dos outros alunos. (Mãe de estudante do $3^{\circ}$ ano do Ensino Fundamental)

Em meio às questões sobre os planos e estratégias a serem adotados para garantir uma aprendizagem durante a pandemia de Covid-19, salienta-se que as atividades remotas permanecerão pelos próximos meses, na rotina de estudantes de todo o país. O cotidiano da família foi modificado inesperadamente, a autonomia e responsabilidade pela aprendizagem e estudo dos filhos foram habilidades muito requeridas neste cenário. No entanto sabemos das realidades adversas de muitas famílias. Em relação à rotina e local de estudos durante o isolamento social, os familiares discorreram: 
É um pouco complicado porque a gente não tem uma estrutura, [...] A gente tem uma casa pequena, moramos numa ocupação, por exemplo, e aqui as pessoas e as casinhas são pertinho da outra, então se escuta o que o vizinho tá falando. Isso tudo desconcentra a criança. A gente monta um espaço pra por os menores, espalhamos livros no chão, colocamos um tapete, fazemos leitura e tudo mais. (Mãe de estudantes do $2^{\circ}$ e $4^{\circ}$ ano do Ensino Fundamental)

Eu tenho um neto que ele está fazendo o último ano [...] ele é responsável por criar como se fosse uma rotina de estudo pra todo mundo, ele bota na mesa, o local é aqui na minha cozinha. [...] Ele sabe que eu não sou formada, não tenho estudo, né? Então o pouco que eu aprendi, foi com ele [...]. (Avó de estudantes do $3^{\circ}, 4^{\circ}$ e $5^{\circ}$ ano do Ensino Fundamental)

Os relatos evidenciam aspectos que reconhecemos. Famílias que moram em espaços pequenos, em bairros desassistidos e estrutura precária, relações familiares conflituosas, muitos membros habitando na mesma casa, são alguns exemplos de situações que desfavorecem a organização de uma rotina e espaço de estudos para as crianças em casa. O esforço dos pais torna-se intenso por conta destas realidades. Mais ainda pelo desafio de dar conta das atividades curriculares que as crianças são solicitadas a cumprir. Os pais reclamam da demanda de tarefas que as escolas municipais e estaduais requeriam. Destacaram que o inicio do Ensino Remoto foi marcado pelo excesso de atividades diárias, o que acarretou no atraso do envio das respostas e no cansaço e desinteresse das crianças pelos estudos: “[...] os professores, eu acho que eles não sabiam o que fazer e passavam muitas coisas para os alunos não ficarem atrasados [...] A gente começa uma hora da tarde e termina as coisas todas até cinco horas e nem sempre temos o tempo livre". (Avó de estudantes do $3^{\circ}, 4^{\circ}$ e $5^{\circ}$ ano do Ensino Fundamental)

As famílias abordaram pontos comuns em seus relatos, como a falta de local adequado para os estudos, a quantidade de conteúdos repassados diariamente, as falhas nas interações dos alunos, pais e professores por conta do precário acesso à internet, etc. Estudantes das escolas pesquisadas apontaram que as apostilas entregues antecipadamente foram uma das soluções que minimizaram os impactos do Ensino Remoto, já que muito não tem acesso à internet, ou um aparelho celular disponível para realização das atividades. Como destacam:

Às vezes não temos internet disponível o tempo todo, ele passa alguns dias com o pai e lá ele consegue utilizar melhor para baixar vídeos aulas da internet, ele ouve o que a professora está falando, mas ele não gosta muito desse formato [...]. (Mãe de estudante do $2^{\circ}$ ano do Ensino Fundamental). 
Eles acompanharam a aula pela rádio e atividades das apostilas, só que eles mesmos dizem assim: vovó, mas não é legal, a gente quer ter contato com nossas professoras, a gente faz perguntas, é difícil assim [...]. (Avó de estudantes do $3^{\circ}, 4^{\circ}$ e $5^{\circ}$ ano do Ensino Fundamental)

A aprendizagem não foi como a gente espera na escola [...]. Muitas das atividades realmente foram copiadas e não foram explanadas, realmente, explicadas [...]. Só explicava mesmo pra responder. Então, tem professores que se dedicam a ensinar mesmo como também tem professores que fizeram como muitos pais, só estavam pra ajudá-los pra responder e pronto. E eu fui uma, ajudei muito, mas pra responder. (Mãe de estudante do $4^{\circ}$ ano do Ensino Fundamental).

Segundo Oliveira, Gomes, Barcellos (2020) se no Ensino presencial o papel do professor é fundamental, no Ensino remoto isso, provavelmente, se intensifica inclusive pela ausência de familiaridade com tecnologias e técnicas eficazes de ensino a distância. Isso resultará na manutenção ou ampliação das desigualdades sociais e de acesso ao ensino e aprendizagem.

Acerca do desempenho das crianças no processo de aprendizagem integralmente em casa, os pais e responsáveis dividem opiniões. Para três familiares, os filhos obtiveram aprendizagem e que a escola e professores se empenharam em auxiliar nas atividades. Para sete responsáveis não houve uma aprendizagem válida e favorável na obtenção de conhecimentos pelas crianças:

Identificamos que os alunos se sentem desmotivados com o Ensino Remoto por conta da falta de interação e de como é aplicado, caracterizado por uma didática unilateral, em que apenas o professor dá as informações e aguarda a entrega das atividades com as respostas dos exercícios. No decorrer do diálogo com os responsáveis, embora os desafios e dificuldades vivenciados em seus lares por conta do Ensino Remoto, eles destacam quais estratégias pedagógicas deram certo com seus filhos. Diante disso, algumas escolas adotaram atividades mais práticas e dinâmicas como a produção de jogos e brincadeiras que oferecem ao aluno um papel mais construtivo no processo de aprendizagem. Apesar de não ser fácil levar interação à distância para crianças com os poucos recursos tecnológicos, houve pais que se sentiram satisfeitos com algumas estratégias utilizadas pelos professores:

[...] quando as atividades estão ligadas ao nosso cotidiano, sobre matemática, por exemplo, os professores incentivam a fazer cálculos com as coisas que temos em casa, usamos frutas ou objetos. Além do mais, atividades de educação física também tem isso, ele gosta de 
praticar exercícios, nós formamos tudo e assim ele se sente bem, essas atividades que envolvem um trabalho em equipe, comigo e com pai dele, são as favoritas dele. Sempre estamos com ele, porém foi a primeira vez que ficamos mais ativos na hora da aprendizagem, e confirmamos como é importante estar perto do filho sempre. (Mãe de estudante do $4^{\circ}$ ano do Ensino Fundamental).

Além da participação na rotina de estudos dos estudantes, os familiares tiveram que compreender os sentimentos e conflitos que surgem diante do afastamento das crianças da sala de aula. Devido às situações de estresse causadas pelo isolamento social, os pais esgotam a tolerância, paciência e flexibilidade para entender as dificuldades e auxiliar as crianças em suas necessidades. Uma mãe relata acerca do processo de auxiliar os filhos em casa: "eu acredito que quando estou ensinando e eles erram, eles percebem que eu fico chateada [...]. Então, acaba sendo um bloqueio, o que não aconteceria se fosse com o professor, eu acho. É uma cobrança de mãe, mas eu tento fazer o meu melhor." (Mãe de estudante do $4^{\circ}$ ano do Ensino Fundamental).

A convivência no lar $24 \mathrm{~h}$ por conta do isolamento social e com o Ensino Remoto Emergencial gerou oscilações de humor e emoções desfavoráveis no interior das casas e influenciou no desempenho escolar dos estudantes: "a gente nota que ela fazia atividade por fazer e às vezes sem se empenhar como se empenhava na escola e isso foi muito ruim porque ela apresentou um baixo desempenho, aí coloquei pra se dedicar mais, nada de ficar acordada até tarde, tirei TV, e lazer só depois dos estudos." (Mãe de estudante do $3^{\circ}$ ano do Ensino Fundamental).

O comportamento das crianças segundo os pais foi de irritabilidade e impaciência para desenvolver as atividades no Ensino Remoto. Segundo Stein (2020) “[...] além de estados emocionais diversos por conta das experiências que tiveram durante o período de quarentena, que podem incluir violência doméstica, perda de parentes para a Covid-19 e dificuldades econômicas familiares, já se sabe da diversidade de níveis de aprendizagem durante o período de emergência, podendo incluir até perda de aprendizagem que já se tinha adquirido." Os impactos psicológicos e na saúde dos alunos, professores e gestores devem ser considerados, essas condições emocionais atingiu a aprendizagem das crianças, que ficaram vulneráveis e desestimuladas.

A pesquisa além de dialogar com os familiares e responsáveis dos estudantes, buscou ouvir as crianças para entender seus sentimentos e percepções acerca dos efeitos da pandemia, sobretudo sobre seu processo de aprendizagem escolar. Os estudantes que colaboraram com a pesquisa estão matriculados nas escolas municipais e estaduais do 
município de Parintins, anos iniciais do Ensino Fundamental de $1^{\circ}$ a $5^{\circ}$ ano, na faixa etária de 07 anos a 11 anos.

A realização da conversa com as crianças foi realizada via Whatsapp e por meio de vídeos chamadas e áudios, que posteriormente, foram transcritos. Com questões relacionadas aos desafios que as crianças enfrentam para estudar durante a pandemia, com a participação de nove estudantes, que se expressaram através de textos e desenhos ou fotos que retratam a experiência nesse tempo de isolamento social. Indagados sobre as experiências de estudar em casa, expuseram:

“[...] eu não gostei muito não, porque não consigo compreender as coisas com facilidade [...] os professores, eles ajudam muito nas tarefas, sem eles não dá pra estudar em casa. Então, eu não gostei. E as tarefas daqui de casa na pandemia mudaram bastante, porque invés de ir pra escola eu fico em casa e ajudo minha vó." (Aluno do $5^{\circ}$ ano do EF - 11 anos)

Essa pandemia atingiu todos nós aqui em casa. Não só eu como meus irmãos e minhas irmãs e meus primos que estão lá em Manaus. Estão querendo vim muito pra estudar, não conseguem vir por causa que fechou o porto. A gente não pode fazer muita coisa, não pode sair muito pra passear, não pode um pouco de tirar o peso da cabeça, não pode né? (Aluno do $4^{\circ}$ ano do EF- 10 anos)

Eu sou aluna do terceiro ano, eu fiquei muito triste porque eu não posso ir à escola, tô prejudicada aqui em casa nos trabalhos de aula, não consigo fazer sem ajuda dos professores. (Aluna do $4^{\circ}$ ano do EF-10 anos)

Nota-se que os estudantes sentiram muitas dificuldades no ensino remoto enfatizaram emoções diversas, principalmente medo em relação ao vírus, falta de adaptação com a nova rotina e saudades dos professores e colegas. A situação pandêmica obrigou crianças e familiares a mudarem seus hábitos e estudarem de modo remoto, tudo por meio das mídias digitais, sendo necessário acesso à internet e suportes como computador, tablet ou celulares. Seis estudantes relataram sobre a não disposição de rede de internet ou de computador/ um só celular na família, entre outras situações, que impedem a participação nas aulas não presenciais. A aluna do $4^{\circ}$ ano do $\mathrm{EF}$, destaca seu principal desafio: "não tenho celular, eu tô utilizando da minha avó e as vezes ele fica com problema, as vezes ele descarrega, as vezes ela tá sem tempo pra isso, para estar perto de mim e não tem como compreender bem as coisas no celular[...]". Tal 
problemática levou o distanciamento e a vontade de estudar dos alunos e como consequência gerou o atraso no envio e acúmulo das atividades.

Outro ponto discorrido diz respeito às famílias com crianças de diferentes idades e séries, que resulta no conflito de horários e aumento das brigas entre os estudantes, pois a maioria dos lares possui apenas um único aparelho móvel ou um computador. "[...] não posso usar o notebook porque meu irmão mais velho usa muito e minha mãe acaba levando o celular para o trabalho, então fica impossível de estudar, então não participo da aula, só de noite ou quando dá.” enfatiza o aluno do $3^{\circ}$ ano do EF.

Notamos as diferentes realidades, desde os estudantes que sofrem com a exclusão digital até os que possuem tais ferramentas, mas não tem acesso no horário da aula ou não se sentem estimulados no novo formato. Para os estudantes sem acesso à internet, foram elaboradas apostilas e atividades impressas, contudo nem todos conseguem acompanhar as aulas, uma aluna do $2^{\circ}$ ano do EF destaca: "a vovó não tem condição de fazer cópia pra mim e assim não dá, eu preciso dos professores perto da gente”.

A imagem da sala de aula presencial com o professor ensinando e os colegas ao redor é um dos principais motivos que fazem os alunos se sentirem desestimulados a estudar em casa. Três estudantes discorreram sobre a solidão que sentem com o ensino remoto e com a nova rotina, para os mesmos, estar em casa é sinônimo de brincadeiras e descanso enquanto a escola é o espaço para se dedicar aos estudos, além do mais, a pressão feita pelos pais acaba deprimindo os alunos. "Eu sinto tristeza e eu quero muito voltar [...] minha mãe [...] ela fica muito irritada comigo, porque eu não aprendo, às vezes e não sei fazer minhas tarefas. Eu preciso que a professora me ensine" (Aluno do $4^{\circ}$ ano).

Cinco alunos participaram da entrevista por meio de diálogos por áudio ou vídeo, dois alunos com TEA contaram com o relato somente dos responsáveis e quatro crianças enviaram desenhos que representam sua visão das aulas em casa.

Figura 1 - Desenho feito por aluna do $2^{\circ}$ ano do EF 


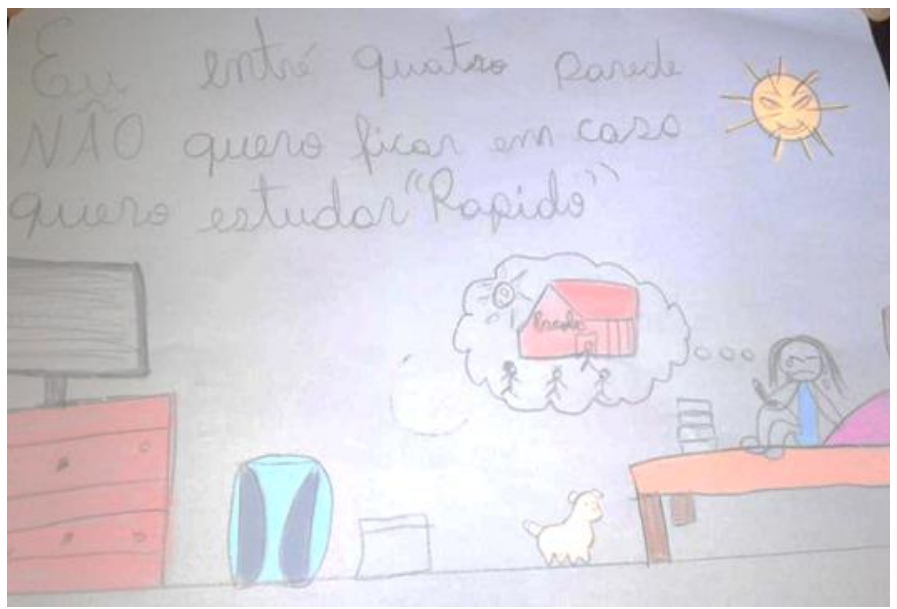

Fonte: acervo da pesquisadora, 2020.

Figura 2 - Desenho feito por aluna do $4^{\circ}$ ano do EF

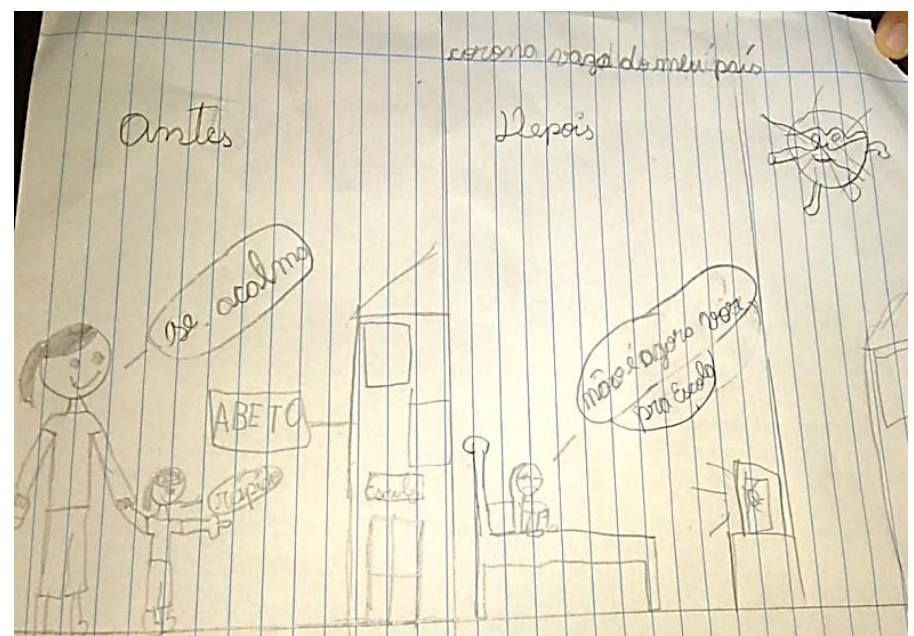

Fonte: acervo da pesquisadora, 2020.

Os desenhos dos estudantes demonstram a nova realidade da educação escolar, acompanhado de frases como: "Eu entre quatro paredes... não quero ficar em casa... quero estudar rápido"; "Corona vaza do meu país". Imagens que representam como era a vida antes da pandemia e como está sendo atualmente, o medo de voltar às aulas com o coronavírus circulando e como a rotina de estudos se resume em pegar o celular e livros. Os estudantes que participaram da pesquisa manifestam o desejo de voltar às aulas presenciais e rever principalmente seus professores, para as crianças a aprendizagem só ocorre de forma efetiva e mais prazerosa na sala de aula e com interação entre os colegas.

\section{Considerações Finais}


$\mathrm{O}$ atual contexto educacional gerou mudanças significativas nos currículos escolares e afetou diretamente os processos educativos, a formação dos professores e uso das ferramentas tecnológicas na aprendizagem das crianças. As dificuldades e desafios de professores, pais e alunos se acentuaram com a obrigatoriedade do Ensino Remoto, uma das medidas adotadas durante o isolamento social que suscitou mudanças repentinas nas práticas escolares, novas definições e organização curriculares, diferentes formatos de aulas, procedimentos avaliativos e a relação família-escola.

Atender as etapas de ensino e aprendizagem nos anos iniciais e garantir a aprendizagem dos alunos tornou-se um desafio ainda maior. As atividades escolares adentraram as casas dos estudantes, com isso, pais e adultos passaram a "atuar" como professores (as). E os estudantes, embora tentem resistir a essa rotina, por conta das cobranças e estresses causados, ou por não possuírem um espaço favorável para realização das tarefas escolares e não poderem interagir com os colegas e professores, foram obrigados a estudar neste formato, com isso frustram-se e desanimam bastante. Inclusive criticam o excesso de atividades solicitadas e a falta de recursos e aparelhos para acessar as aulas.

Segundo Kirchner (2020, p.46) "a pandemia nos colocou frente ao desafio de pensar a escola, nos retirando a sala de aula, o ambiente que sempre foi o lugar de estabelecer os vínculos principais de mediações de conhecimento”. A escola perante o cenário educacional pandêmico acaba permeando diversas reflexões, como, a função da instituição escolar na sociedade atual, o papel e formação dos docentes, o desempenho e avaliação dos alunos e os avanços tecnológicos na era da informação. Schutz e Fuchs (2020, p.69) destacam que "em tempos de pandemia, de isolamento social e de desaceleração dos fluxos diários, a discussão sobre o sentido da escola e o seu papel civilizacional se faz necessária." É importante analisar o aluno como ser social, que além do cotidiano escolar, fica vulnerável a inúmeros fatores que dificultam a aprendizagem, já que é irreal imaginar que seja mantido o mesmo currículo, que os professores consigam executar tudo que foi planejado, familiares com tempo para acompanhar as atividades e que os estudantes tenham acesso a diversas plataformas de virtuais durante o horário de aula. A comunidade escolar e o currículo tiveram que se adaptar a uma nova rotina e possibilidades no formato de Ensino Remoto.

As vozes, sentimentos e atitudes dos estudantes e dos pais que participaram da pesquisa evidenciaram as rotinas estressantes e desafiadoras vivenciadas na pandemia, no 
âmbito familiar. Os coordenadores pedagógicos e gestores da educação escolar apontaram as estratégias de ensino utilizadas para enfrentar o momento e garantir o direito de aprender do aluno e o cumprimento dos ofícios do professor. Professores destacam como lidaram com o ensino e aprendizagem, como desenvolveram os conteúdos curriculares, salientando as lacunas e necessidades geradas no contexto do processo de ensino, principalmente nos aspectos da participação dos alunos e necessidade de uma internet de qualidade.

Em síntese, a pesquisa seguiu os objetivos propostos, trouxe resultados concretos e com embasamento teórico-metodológico, contribuindo com os debates e discussões acerca do desenvolvimento das aulas e atividades curriculares em tempos de pandemia, das práticas docentes, das alternativas metodológicas construídas para enfrentamento dos embates por parte das secretarias de educação e dos gestores da educação escolar pública. Um conjunto de inquietações e ações geradas pela pandemia da Covid-19

\section{REFERÊNCIAS}

AMAZONAS, Secretaria De Estado de Educação e Desporto do Amazonas (SEDUC). Secretaria Executiva Adjunta Pedagógica. Departamento de Políticas e Programas Educacionais. Diretrizes Pedagógicas para o Regime Especial de Aulas Não Presenciais. Disponível em http://www.educacao.am.gov.br/wpcontent/uploads/2020/03/DIRETRIZES-PEDAGoGICAS-23.03.pdf. Acesso em: 03 abr. 2021.

ALMEIDA, F. J. de; ALMEIDA, M. E. B. de; SILVA, M. G. M. da (orgs). De Wuhan a Perdizes: trajetos educativos [recurso eletrônico] / - São Paulo: EDUC, 2020.

ALVES, L. Educação remota: entre a ilusão e a realidade. Interfaces Científicas, vol.8, $\mathrm{n}^{\circ} 3$, p. $348-365$, Aracaju, 2020.

BRASIL, Ministério da Educação. Base Naconal Comum Curricular. MEC, Brasília, 2017.

BRASIL. CONSELHO NACIONAL DE EDUCAÇÃO. Parecer CNE/CP n. 5/2020. Disponível em: http://portal.mec.gov.br/index.phpoption=com_docman\&view=download\&alias $=145011$-pcp005-20\&ca-tegory_slug=marco-2020pdf\&Itemid=30192. Acesso em: 20 mai. 2020

BOTO, C. A educação e a escola em tempos de coronavírus, Jornal da USP. Disponível em: https://jornal.usp.br/artigos/a-educacao-e-a-escola-em-tempos-de-coronavirus/. Acesso em: 26 jun. 2020.

BLIKSTEIN, P. et al. Como estudar em tempos de pandemia. Disponível em: 
https://epoca.globo.com/como-estudar-em-tempos-de-pandemia-24318249. Acesso em: 24 jun. 2020.

DALBEN, A. I. L.. Relação Família x Escola em Tempos de Pandemia. Belo Horizonte: Revista Paidéia, FUMEC, $\mathrm{n}^{\circ}$ 22, 2020.

ESTRELLA, B; LIMA, L. CNE aprova diretrizes para escolas durante a pandemia. Disponível em: http://portal.mec.gov.br/busca-geral/12-noticias/acoes-programas-eprojetos-637152388/89051-cne-aprova-diretrizes-para-escolas-durante-a-pandemia. Acesso: 24 jun. 2020.

ENSINO a distância na Educação Básica frente à pandemia da Covid-19. Todos pela Educação. Abril, 2020. Disponível em: https://www.todospelaeducacao.org.br/uploads/_posts/425.pdf. Acesso em: jul. 2020.

FELDMANN, M. G; SENSATO, M. G.; MARTINS, L. W.. Diversidade no currículo ou currículo na diversidade: qual o lugar? In: FELDMANN, M. G; SENSATO, M. G.; MARTINS, L. W. De Wuhan a Perdizes: trajetos educativos [recurso eletrônico]/ - São Paulo: EDUC, 2020, p. 46- 53.

GUIZZO, B. S.; MARCELLO, F. A.; MÜLLER, F. A reinvenção do cotidiano em tempos de pandemia. São Paulo: Educ. Pesqui. vol. 46, 2020.

KIRCHNER, Elenice Ana. Vivenciando os Desafios da Educação em Tempos de Pandemia. Cruz alta: Ilustração, 2020. n.108, p.555-578, Julho, 2020, p. 45 a 53.

LOPES, A. C.; MACEDO, E. Teorias de Currículo. São Paulo: Cortez, 2011 p. 19- 121.

MACEDO, R. S. Currículo: campo, conceito e pesquisa. Petrópolis. Vozes, 2007.

OLIVEIRA, J. Batista. Araújo; GOMES, M.; BARCELLOS, T. A Covid-19 e a volta às aulas: ouvindo as evidências. Rio de Janeiro: Ensaio, aval . pol .públ. Educ, vol.28 no $108,2020$.

PLAPLER, D. A pandemia como Base Mundial Comum Curricular. Disponível em: http://movinovacaonaeducacao.org.br/biblioteca/a-pandemia-como-base-mundialcomum-curricular/. Acesso: 24 jun. 2020.

PALU, J; SCHUTZ, J. A.; MAYER, L. Desafios da educação em tempos de pandemia. Cruz alta: Ilustração, 2020. N.108, p.555-578, Julho, 2020.

SANCRISTÁN, J. G. Saberes e Incertezas do Currículo. Porto Alegre: Penso, 2013.

SILVA, T. T. da. Documentos de Identidade: uma introdução às teorias do currículo. Belo Horizonte: Editora Autentica, 2007. 
SCHÜTZ, J. A.; FUCHS, C. Pensar a (Im) Possibilidade da Escola em Tempos de Pandemia: reflexões à luz de Masschelein e Simons. Desafios da Educação em Tempos de Pandemia, Cruz alta: Ilustração, 2020. N.108, p.555-578, Julho, 2020. p. 69 - 85.

Recebido em: 01/09/2021

Aprovado em: 12/09/2021

Publicado em: 16/09/2021 